\title{
Extraction socket healing in rats treated with bisphosphonate: Animal model for bisphosphonate related osteonecrosis of jaws in multiple myeloma patients
}

\author{
Mehmet Ali-Erdem ${ }^{1}$, Abdulkadir Burak-Cankaya ${ }^{1}$, Sabri Cemil-Isler ${ }^{1}$, Sabit Demircan ${ }^{1}$, Merva Soluk ${ }^{2}$, \\ Cetin Kasapoglu ${ }^{3}$, Cuneyt Korhan-Oral ${ }^{3}$
}

\footnotetext{
${ }^{1}$ Research Assistant, Department of Oral \& Maxillofacial Surgery, Faculty of Dentistry, Istanbul University, Istanbul, Turkey ${ }^{2}$ Research Assistant, Department of Tumour Pathology and Oncologic Cytology, Institute of Oncology, Faculty of Medicine, Istanbul University, Istanbul, Turkey

${ }^{3}$ Professor, Department of Oral \& Maxillofacial Surgery, Faculty of Dentistry, Istanbul University, Istanbul, Turkey
}

Correspondence:

Istanbul University,

Department of Oral \& Maxillofacial Surgery, 34093 Çapa-Fatih, Istanbul Turkey,

sabitdemircan@hotmail.com

Received: $12 / 06 / 2010$

Accepted: 08/12/2010

\begin{abstract}
Ali-Erdem M, Burak-Cankaya A, Cemil-Isler S, Demircan S, Soluk M, Kasapoglu C, Korhan-Oral C. Extraction socket healing in rats treated with bisphosphonate: Animal model for bisphosphonate related osteonecrosis of jaws in multiple myeloma patients. Med Oral Patol Oral Cir Bucal. 2011 Nov 1;16 (7):e879-83.

http://www.medicinaoral.com/medoralfree01/v16i7/medoralv16i7p879.pdf
\end{abstract}

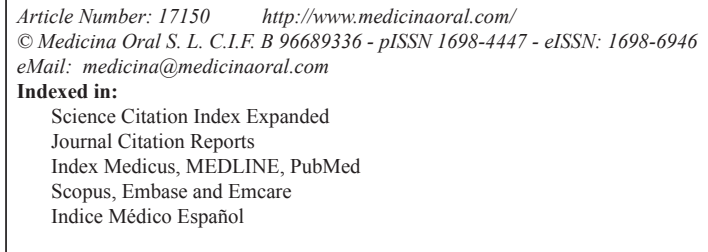

\begin{abstract}
Aim: The aim of this study is to replicate both clinical and histological presentation of bisphosphonate induced osteonecrosis of the jaws (BONJ) in an animal model of the disease state. Successful recapitulation of a BONJlike indication in an animal model will be useful for studying pathogenesis, as well as prevention and treatment strategies for BONJ.

Materials and Methods: Eighty (80) rats were prospectively and randomly divided into two groups; control group(40) and study group(40). All animals in study group, injected with a dose of $1 \mathrm{mg} / \mathrm{kg}$ dexamethasone (DX) subcutaneously on day 7,14 , or 21 ; and 1,2 , or 3 doses of $7.5 \mu \mathrm{g} / \mathrm{kg}$ zoledronic acid (ZA) subcutaneously administered to coincide with the last day of DX. Half of the animals from each group underwent extraction of the left mandibular molars and the remaining animals underwent extraction of the left maxillary molars under pentobarbital-induced general anesthesia. All animals were euthanized twenty-eight (28) days following tooth extractions.

Results: The amount of new bone trabecules as significantly decreased in bisphosphonate-dexamethasone (BPDX) treated sockets. Difference between both groups was found statistically significant $(p=0,0001)$. There's no foreign body reaction in sockets of both groups and no significance difference observed for fibrosis $(p=0,306)$. The necrosis scores were significantly higher in BP-DX treated sockets $(\mathrm{p}=0,015)$. The inflamation scores were significantly higher for study group $(\mathrm{p}=0,0001)$.

Conclusion: This study provides preliminary observations for the development of an animal model of BONJ. But we think that there is need for other studies have only BP treated group and larger study population.
\end{abstract}

Key words: Bisphosphonate, osteonecrosis, extraction socket, rat. 


\section{Introduction}

Bisphosphonates (BPs) are a group of medication used in clinical settings for over thirty years to inhibit bone resorption (1). They are used to treat patients with multiple myeloma, metastatic disease of the skeleton (2) and they are also effective in patients with Paget's disease of bone and osteoporosis (3).

A recognized side effect of $\mathrm{BP}$ is osteonecrosis of jaws (BONJ) $(4,5)$. Overwhelmingly, the majority of reported BONJ cases are associated with infused nitrogen containing bisphosphonates (zoledronic acid or pamidronate) used for patients with multiple myeloma or breast cancer.6 While the overall incidence of this condition among patients at risk has yet to be defined, a recent report places it between $1 \%$ and $10 \%$. A full understanding of the natural history of the condition, as well as risk factors associated with it, is evolving. Nevertheless, it appears that the duration of intravenous BP therapy, dental manipulation, patient age and the site of bone (mandible versus maxilla) all contribute to the increased likelyhood of a patient developing BONJ $(6,7)$. While BONJ appears to be self-limiting, patients may suffer from bothersome necrotic lesions as well as painful ulcerations overlying areas of necrosis.

The lesions usually occur after dental extractions or oral trauma, but they also occur spontaneously with no history of surgical procedures, trauma, or radiation therapy $(8,9)$. Most of these patients were being treated with intravenous BPs to inhibit skeletal progression in late-stage cancer $(4,9)$. Many of them had a history of malignancy, including multiple myeloma, breast carcinoma, or prostate carcinoma. A definitive mechanism for this "bisphosphonate-associated osteonecrosis" has not yet been identified.

BPs have a non-hydrolysable $\mathrm{P}-\mathrm{C}-\mathrm{P}$ bond and bind with hydroxyapatite of bone. Their ingestion by osteoclasts results in anti-bone-resorptive effects. By inhibiting bone resorption, BPs alter normal remodeling, which can reduce the mechanical properties of bone causing accumulation of areas of microdamage (10). Jawbones may be more affected, because of increased bone remodeling in the alveolar region $(11,12)$.

In addition to their effects on osteoclasts, BPs also show antiangiogenic properties, which may play a role in bisphosphonate-related osteonecrosis $(13,14)$. This is evidenced by significantly decreased angiogenesis in endothelial cells treated with zoledronate in vitro, with decreased endothelial cell proliferation, adhesion, and migration (13).

The aim of the study is to replicate both clinical and histological presentation of BONJ in an animal model of the disease state. Successful recapitulation of a BONJlike indication in an animal model will be useful for studying pathogenesis, as well as prevention and treatment strategies for BONJ.

\section{Materials and Methods}

We prepared the study protocol in consideration of preliminary reports.

\section{Experimental animals}

Eighty male Wistar rats (body weight 110-120 g, approximately 5 weeks old) were purchased from DETAM (Istanbul, Turkey). Rats were assigned to either the study group or the control group ( $\mathrm{n}=40$ for each). Animals were acclimatized prior to the start of the study and any animal observed to be in poor condition was rejected from study inclusion. Rats were housed in cages provided with filtered air at a temperature of $70^{\circ} \mathrm{F} \pm 5^{\circ}$ and $50 \pm 20 \%$ relative humidity. A $12 \mathrm{~h}$ light/dark cycle was maintained. Animals were fed with a standard diet of rat chow and watered ad libitum. All experiments were performed in accordance with the Guidelines for Animal Experiments of the Faculty of Medicine, Istanbul University, Istanbul, Turkey.

\section{Experimental methods and design}

Eighty (80) rats were prospectively and randomly divided into two groups, control group (40) and study group (40). All animals in study group injected with a dose of $1 \mathrm{mg} / \mathrm{kg}$ dexamethasone (DX) subcutaneously on day 0 , 7, or 14; and 1,2, or 3 doses of $7.5 \mu \mathrm{g} / \mathrm{kg}$ zoledronic acid (ZA) subcutaneously, administered to coincide with the last day of DX. In the control group, physiological saline was injected into the same area. Rats were anesthetized before injection using diethyl ether.

Extractions were performed the day following the last injections. Half of the animals from each group underwent extraction of the left mandibular molars and the remaining animals underwent extraction of the left maxillary molars with a dental explorer under pentobarbital-induced general anesthesia.

Five animals from study group and two animals from control group were excluded because these animals died before sacrification date. All animals were euthanized twenty-eight (28) days following tooth extractions. Jaws including the extraction site were resected.

Histopathological observations

Bone samples were decalcified in 10\% EDTA ( $\mathrm{pH}$ 7.2) at $4{ }^{\circ} \mathrm{C}$ for 21 days. Decalcified samples were embedded in paraffin using the standard method, and then a series of $5 \mu$ sections were prepared. Hematoxylin-eosin (HE)stained sections were observed using a light microscope (Eclipse E600; Nikon, Tokyo, Japan).

"Olympus Soft imaging system analySIS FIVE" system is used. Digital images are prepared under 400 magnification and inflammation, necrosis, fibrosis and new bone regeneration are investigated. Inflammation and fibrosis have been given $+(\% 1-30),++(\% 30-60)$ or $+++(>\% 60)$ scores according to their surface covering. Necrosis of tissue samples was noted as yes or no and was used to determine the percentage of animals with necrosis. For new bone regenaration if there's no bone formation (-), 
\%1-30 bone formation ( + ), \%30-60 bone formation ( ++ ) and for $>\% 60(+++)$ scores are given. Additionaly foreign body reaction noted as present or absent.

Statistical analysis

We used + score for the data between $0-30,++$ score for the data between 31-60 and +++ score for the data higher than 60. So we transformed the continues data to non-continues data. That's why we prefered chi-square test.

The significance of differences between both groups was evaluated with a chi-square test. A p-value of 0.05 was considered statistically significant for all tests.

\section{Results}

In general, animals tolerated the procedure well and demonstrated good hemostasis and rapid recovery from anesthesia. Gross evidence of extraction site healing was seen in the majority of both groups in 28 days.

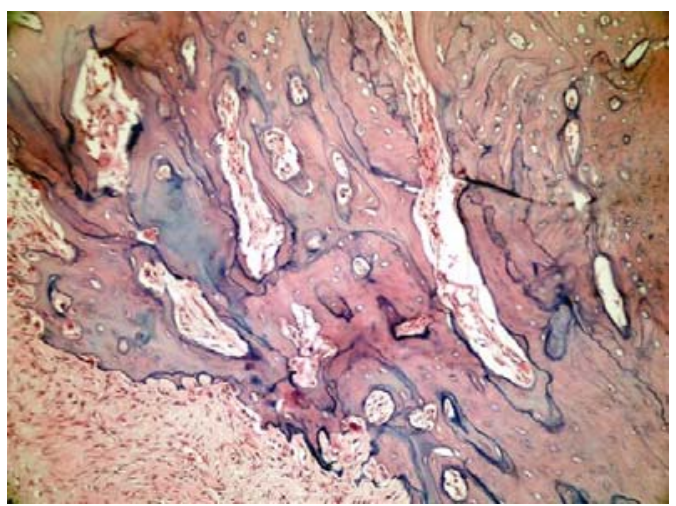

Fig 1. The amount of new bone trabeculaes was significantly decreased in BP-DX treated sockets (Study group, $H \& \mathrm{E} \times 200)$.

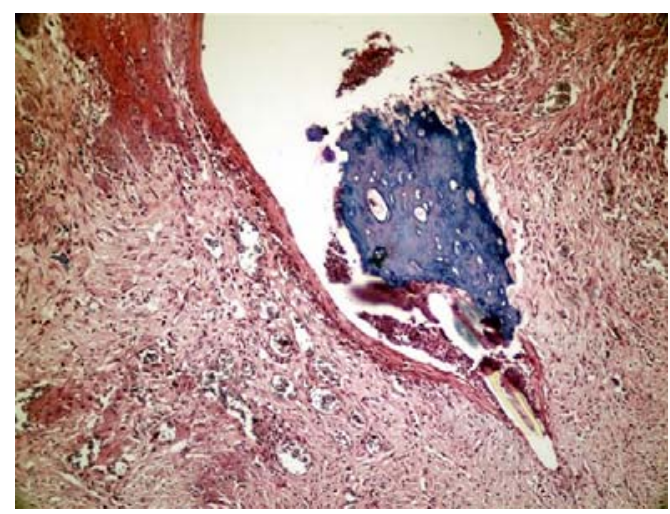

Fig 2. Fistula formation over the necrotic bone area and granulation tissue under the epithelium (Study group, $\mathrm{H} \& \mathrm{E} \times 400)$.

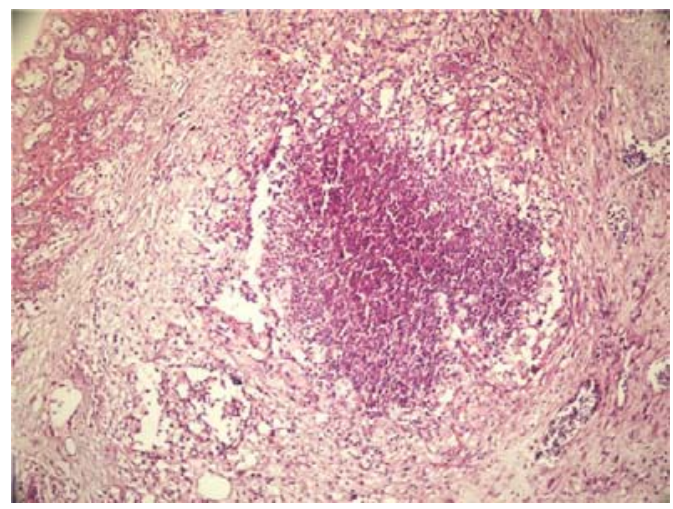

Fig 3. Absess center in the granulation tissue around the extraction socket (Study group, H\&E x200).

Table 1. Statistical observations for study and control groups.

\begin{tabular}{|c|c|c|c|c|c|c|}
\hline & & Stu & Group & & col Group & \\
\hline \multirow{4}{*}{$\begin{array}{l}\text { New Bone } \\
\text { Formation }\end{array}$} & $(-)$ & 10 & $28,60 \%$ & 0 & $0,00 \%$ & \\
\hline & $(+)$ & 16 & $45,70 \%$ & 0 & $0,00 \%$ & \\
\hline & $(++)$ & 9 & $25,70 \%$ & 18 & $47,40 \%$ & $x^{2}: 48,96$ \\
\hline & $(+++)$ & 0 & $0,00 \%$ & 20 & $52,60 \%$ & $\mathrm{P}=0,0001$ \\
\hline \multirow{4}{*}{ Inflammation } & $(-)$ & 1 & $2,90 \%$ & 16 & $42,10 \%$ & \\
\hline & $(+)$ & 16 & $45.70 \%$ & 18 & $47,40 \%$ & \\
\hline & $(++)$ & 15 & $42,90 \%$ & 4 & $10,50 \%$ & $x^{2}: 22,64$ \\
\hline & $(+++)$ & 3 & $8,60 \%$ & 0 & $0,00 \%$ & $\mathrm{P}=0,0001$ \\
\hline \multirow{2}{*}{ Necrosis } & No & 14 & $40,00 \%$ & 26 & $68,40 \%$ & $x^{2}: 5,94$ \\
\hline & Yes & 21 & $60,00 \%$ & 12 & $31,60 \%$ & $\mathrm{P}=0,015$ \\
\hline \multirow{3}{*}{ Fibrosis } & $(+)$ & 17 & $48,60 \%$ & 24 & $63,20 \%$ & \\
\hline & $(++)$ & 17 & $48,60 \%$ & 14 & $36.80 \%$ & $x^{2}: 2,37$ \\
\hline & $(+++)$ & 1 & $2,90 \%$ & 0 & $0,00 \%$ & $\mathrm{P}=0,306$ \\
\hline $\begin{array}{c}\text { Foreign Body } \\
\text { Reaction }\end{array}$ & $(-)$ & 35 & $100,00 \%$ & 38 & $100,00 \%$ & \\
\hline
\end{tabular}


28 days after tooth extraction, resorption of residual interdental bone septum by osteoclasts as well as formation of new bone trabeculaes were viewed in sockets of both groups. However, the amount of new bone trabeculaes was significantly decreased in BP-DX treated sockets (Fig. 1). This difference between both groups was found statistically significant $(\mathrm{p}=0,0001)$.

There is no foreign body reaction in sockets of both groups and no significant difference was observed for fibrosis $(p=0,306)$. Necrosis scores were significantly higher in BP-DX treated sockets $(p=0,015)$ (Fig. 2). Inflamation scores were significantly higher for BP-DX treated group $(p=0,0001)$. By day 28 , the intensity of the inflammatory infiltrate in study group was mild to moderate (Fig. 3) ( Table 1).

\section{Discussion}

In the present study we aimed to replicate both clinical and histological presentation of BONJ in an animal model of the disease state. Successful recapitulation of a BONJ-like indication in an animal model will be useful for studying pathogenesis, as well as prevention and treatment strategies for BONJ.

There have been several recent reports of BONJ occurring after oral surgery (e.g., tooth extraction) in patients (especially cancer patients) undergoing long-term BP treatment.

Our primary interest in bisphosphonates focused on the patient population with multiple myeloma, thus we used cycles of ZA and included a concomitant course of DX to mimic the regimen typically given to patients with multiple myeloma.

In previous histological studies on healing of extraction sockets in normal rats, it has been found that new bone begins to form on the floor of the extraction socket about 2 days after extraction, and the extraction socket becomes filled with newly formed bone 14 days after extraction $(15,16)$. In present study; 28 days post-extraction, complete epithelialization of the extraction sites was observed only in control animals. In contrast, clinical and histological evidence of delayed healing, as manifested by exposed bone or ulceration, was seen in many of ZA/DX-treated animals.

Hikita et al. (17) observed that healing of the extraction socket was delayed in rats with impairment of bone resorption caused by inhibition of osteoclast function began just after tooth extraction as a result of the alendronate pretreatment. In studies of the effect of BPs on bone formation, Yamamoto et al. (18) and Tabuchi et al. (19) found that osteoclasts appeared prior to osteoblasts, and that activation of osteoclasts influenced the subsequent promotion of bone formation in various ways. These results suggest that inhibition of osteoclast formation just after extraction is related to delayed initial healing. In present study; the amount of new bone trabeculaes was significantly decreased in BP-DX treated sockets.

Ulcerative changes were present in the majority of ZA/ DX-treated rats. Reid et al. propose that damage to the alveolus initiated by procedures or other trauma results in the local release of bound bisphosphonates into the surrounding tissue. The released bisphosphonates are toxic to the overlying epithelium and can result in inhibition of proliferation and wound healing (20). Additional study is clearly needed to clarify the process which underlies ulcerative changes.

The character of the inflammatory infiltrate differ appreciably between control and study groups. By day 28 , the intensity of the inflammatory infiltrate in study group was mild to moderate.

Hikita et all reported that if BP first administered just after tooth extraction, effects processes such as hypocalcemia first appeared during the later stages of the healing (17). However, in the present study administration of BP prior to tooth extraction, such that the tooth was extracted under the active pharmacological influence of BP, caused initial healing of the extraction socket to be delayed. These data show that the timing of BP administration can strongly affect the healing of the extraction socket.

Our results well matched with the results of another study focused on the multiple myeloma patients. This study had similar doses for DX-BP and similar results reported for osteonecrosis (21).

This study provides preliminary observations for the development of an animal model of BONJ. Successful recapitulation of a BONJ-like indication in an animal model will be useful for studying pathogenesis, as well as prevention and treatment strategies for BONJ. We belive that we recapulate the BONJ-like indication in an animal model. But there is need for more studies with other BP and DX doses, timings and larger study groups to define the DX and BP doses and timings for prevention of BONJ in multiple myeloma population and effective evaluation of treatment options for BONJ.

\section{References References with links to Crossref-DOI}

1. Rogers MJ, Watts DJ, Russell RG. Overview of bisphosphonates. Cancer. 1997;80:1652-60.

2. Coleman RE. Future directions in the treatment and prevention of bone metastases. Am J Clin Oncol. 2002;25:S32-8.

3. Holen I, Coleman RE. Bisphosphonates as treatment of bone metastases. Curr Pharm Des. 2010;16:1262-71.

4. Marx RE. Pamidronate (Aredia) and zoledronate (Zometa) induced avascular necrosis of the jaws: a growing epidemic. J Oral Maxillofac Surg. 2003;61:1115-7.

5. Hansen T, Kunkel M, Weber A, James Kirkpatrick C. Osteonecrosis of the jaws in patients treated with bisphosphonates - histomorphologic analysis in comparison with infected osteoradionecrosis. $\mathrm{J}$ Oral Pathol Med. 2006;35:155-60.

6. Flichy-Fernández AJ, Balaguer-Martínez J, Peñarrocha-Diago M, Bagán JV. Bisphosphonates and dental implants: current problems. Med Oral Patol Oral Cir Bucal. 2009;14:E355-60.

7. Marx RE, Cillo JE Jr, Ulloa JJ. Oral bisphosphonate-induced osteonecrosis: risk factors, prediction of risk using serum CTX testing, 
prevention, and treatment. J Oral Maxillofac Surg. 2007;65:2397-

410.

8. Pérez SB, Barrero MV, Hernández MS, Knezevic M, Navarro JM, Millares JR. Bisphosphonate-associated osteonecrosis of the jaw. A proposal for conservative treatment. Med Oral Patol Oral Cir Bucal. 2008;13:E770-3.

9. Ruggiero SL, Mehrotra B, Rosenberg TJ, Engroff SL. Osteonecrosis of the jaws associated with the use of bisphosphonates: a review of 63 cases. J Oral Maxillofac Surg. 2004;62:527-34.

10. Mashiba T, Hirano T, Turner CH, Forwood MR, Johnston CC, Burr DB. Suppressed bone turnover by bisphosphonates increases microdamage accumulation and reduces some biomechanical properties in dog rib. J Bone Miner Res. 2000;15:613-20.

11. Zaki Ae, Vanhuysen G. Histology of the periodontium following tooth movement. J Dent Res. 1963;42:1373-9.

12. Rygh P. Ultrastructural changes in pressure zones of human periodontium incident to orthodontic tooth movement. Acta Odontol Scand. 1973;31:109-22.

13. Wood J, Bonjean K, Ruetz S, Bellahcène A, Devy L, Foidart JM, et al. Novel antiangiogenic effects of the bisphosphonate compound zoledronic acid. J Pharmacol Exp Ther. 2002;302:1055-61.

14. Fournier P, Boissier S, Filleur S, Guglielmi J, Cabon F, Colombel $\mathrm{M}$, et al. Bisphosphonates inhibit angiogenesis in vitro and testosterone-stimulated vascular regrowth in the ventral prostate in castrated rats. Cancer Res. 2002;62:6538-44.

15. Pietrokovski J, Massler M. Ridge remodeling after tooth extraction in rats. J Dent Res. 1967;46:222-31.

16. Johansen JR. Repair of the post-extraction alveolus in the Wistar rat. A histologic and autoradiographic study. Acta Odontol Scand. 1970;28:441-61.

17. Hikita H, Miyazawa K, Tabuchi M, Kimura M, Goto S. Bisphosphonate administration prior to tooth extraction delays initial healing of the extraction socket in rats. J Bone Miner Metab. 2009;27:66372 .

18. Yamamoto Y, Udagawa N, Matsuura S, Nakamichi Y, Horiuchi $\mathrm{H}$, Hosoya A, et al. Osteoblasts provide a suitable microenvironment for the action of receptor activator of nuclear factor-kappaB ligand. Endocrinology. 2006;147:3366-74.

19. Tabuchi M, Miyazawa K, Kimura M, Maeda H, Kawai T, Kameyama Y, et al. Enhancement of crude bone morphogenetic proteininduced new bone formation and normalization of endochondral ossification by bisphosphonate treatment in osteoprotegerin-deficient mice. Calcif Tissue Int. 2005;77:239-49.

20. Reid IR, Bolland MJ, Grey AB. Is bisphosphonate-associated osteonecrosis of the jaw caused by soft tissue toxicity? Bone. 2007;41:318-20.

21. Sonis ST, Watkins BA, Lyng GD, Lerman MA, Anderson KC. Bony changes in the jaws of rats treated with zoledronic acid and dexamethasone before dental extractions mimic bisphosphonate-related osteonecrosis in cancer patients. Oral Oncol. 2009;45:164-72. 